(c) American Dairy Science Association, 2004.

\title{
Risk of Disease from Wildlife Reservoirs: Badgers, Cattle, and Bovine Tuberculosis
}

\author{
M. Scantlebury, ${ }^{1, *}$ M. R. Hutchings, ${ }^{2}$ D. J. Allcroft, ${ }^{3}$ and S. Harris ${ }^{1}$ \\ ${ }^{1}$ School of Biological Sciences, University of Bristol, \\ Bristol BS8 1UG, UK \\ ${ }^{2}$ Animal Nutrition and Health Department, SAC, Bush Estate, Penicuik, \\ Midlothian, EH26 8DP, UK \\ ${ }^{3}$ BioSS, JCMB, The King's Buildings, Mayfield Road, \\ Edinburgh, EH9 3JZ, UK
}

\begin{abstract}
Livestock face complex foraging options associated with optimizing nutrient intake while being able to avoid areas posing risk of parasites or disease. Areas of tall nutrient-rich swards around fecal deposits may be attractive for grazing, but might incur fitness costs from parasites. We use the example of dairy cattle and the risks of tuberculosis transmission posed to them by pastures contaminated with badger excreta to examine this trade-off. A risk may be posed either by aerosolized inhalation through investigation or by ingestion via grazing contaminated swards. We quantified the levels of investigation and grazing of 150 dairy cows at badger latrines (accumulations of feces and urine) and crossing points (urination-only sites). Grazing behavior was compared between strip-grazed and rotation-grazed fields. Strip grazing had fields subdivided for grazing periods of $<24 \mathrm{~h}$, whereas rotational grazing involved access to whole fields for 1 to $7 \mathrm{~d}$ each. A higher proportion of the herd investigated badger latrines than crossing points or controls. Cattle initially avoided swards around badger latrines but not around crossing points. Avoidance periods were shorter in strip- compared with rotation-grazing systems. In rotation-grazing management, latrines were avoided for longer times, but there were more investigative contacts than with strip-grazing management. If investigation is a major route of tuberculosis transmission, the risk to cattle is greatest in extensive rotation-grazing systems. However, if ingestion of fresh urine is the primary method of transmission, strip-grazing management may pose a greater threat. Farming systems affect the level and type of
\end{abstract}

\footnotetext{
Received May 21, 2003.

Accepted October 1, 2003.

Corresponding author: M. Scantlebury; e-mail: m.scantlebury@ zoology.up.ac.za.

${ }^{1}$ Current address: Mammal Research Institute, Department of Zoology and Entomology, University of Pretoria, Pretoria 0002, South Africa.
}

contact between livestock and wildlife excreta and thus the risks of disease.

(Key words: bovine tuberculosis, dairy cow, lactation, nutrition)

Abbreviation key: OMD = organic matter digestibility, $\mathbf{T B}=$ tuberculosis, $\mathbf{W}=$ Wald statistic.

\section{INTRODUCTION}

Mammalian herbivores make complex foraging decisions and are able to optimize both nutrient and energy intake by distinguishing among different species and different characteristics of swards (Arnold, 1981; Parsons et al., 1994). They may use both sward height and sward darkness as cues to determine potential forage intake rate and nitrogen content of the sward, respectively (Black and Kenney, 1984; Arnold, 1987; Bazely and Ensor, 1989; Bazely, 1990). The deposition of feces and the leaching of nutrients from feces into surrounding swards often result in patches of relatively tall and nutrient-rich sward around fecal deposits (Edwards and Hollis, 1982; Haynes and Williams, 1993). Areas around fecal deposits have the potential to be highly desirable to grazing herbivores but represent a high risk of disease and parasitism via the fecal-oral route (Sykes, 1987). Species may opt to avoid lush, yet potentially contaminated areas by detecting smells or tastes that signify the contamination. Foraging decisions can then be interpreted in relation to the relative costs and benefits of grazing contaminated areas (Hutchings et al., 1999, 2000; Hutchings et al., 2001). The grazing behavior of herbivores may also be expected to vary in relation to the type of agricultural system being employed. For example, in nutrient-poor systems, the fertilizing effect of excreta may make areas around fecal deposits highly attractive to herbivores compared with the rest of the field. By comparison, in intensive agricultural systems, the increased use of fertilizers may mean that the entire sward is homogenously tall and dark; consequently there may be less attraction to areas around fecal-contaminated sward. 
There is evidence linking Mycobacterium bovis infection in badgers (Meles meles) with outbreaks of tuberculosis (TB) in cattle (Little et al., 1982a, 1982b; Brown et al., 1994; Krebs, 1997). The most plausible route for transmission is thought to be via contact with contaminated pasture (Hutchings and Harris, 1997, 1999). Infectious badgers are believed to contaminate the environment with bacilli excreted in their urine, feces, sputum, and possible pus from abscesses (Muirhead et al., 1974; Wilesmith et al., 1982; Stuart and Wilesmith, 1988). Of these, urine is believed to pose the greatest risk because of the high numbers of bacilli (Gallagher and Horwill, 1977). Badger urinations occur either at latrines (localized accumulations of feces and urine) or on pasture where badger paths cross linear features such as a hedgerows or ditches, known as "crossing points" (accumulations of urine only). Both of these areas are often readily accessible to cattle (Benham and Broom, 1989, 1991; Brown et al., 1994). Bovine tuberculosis can be contracted via a number of routes including ingestion and inhalation, although the relative importance for these routes for the transmission of $M$. bovis from badgers to cattle through contact with contaminated sward is as yet unknown (Morris et al., 1994).

To date, previous work on the potential for TB risk through contact with badger excreta-contaminated pasture in agricultural systems in cattle has been confined to organic suckler beef herds (Hutchings and Harris, 1997). There has been no work on intensive farming systems, especially dairy systems, which make up the majority of TB occurrences in southwest England (MAFF, 1993). Agricultural intensification might affect the contact process between cattle and badger excreta in 2 ways: 1) Increased fertilizer input results in increased grass production enabling higher stocking densities in intensive systems that may affect social interactions between cattle, for example, by increased competition for noncontaminated swards. This might occur when cattle are strip-grazed rather than rotationgrazed (see Materials and Methods for definitions). 2) In high fertilizer input systems badger excreta may have less impact on background soil characteristics, sward nutrient content and thus the relative nutrient benefits associated with latrines and crossing points.

Here we use an intensive dairy system to determine 1) whether the deposition of excreta on pasture by badgers results in a possible trade-off between nutrition and parasitism, 2) whether the type of grazing management may affect the number and duration of investigative and grazing contacts around badger excreta contaminated areas, and 3) whether a particular type of grazing management may pose a greater risk of $\mathrm{TB}$ to cattle.

\section{MATERIALS AND METHODS}

\section{Study Site and Animals}

The grazing behaviors of approximately 150 lactating Holstein Friesian dairy cattle were monitored on a farm in north Devon, southwest England, for a complete grazing year from "turn out" on April 10, 2000, until October 30, 2000, when they were wintered indoors. The herd was chosen because badger latrines and crossing points were in many of the fields to which the cattle had access. Neither the herd nor the badgers were tested for TB during the period of the study; however, TB was spreading rapidly throughout the area. As the aim was to assess the possibilities for disease risk under normal working conditions, cattle behavior was monitored under the grazing regimen selected by the farm manager.

The calving pattern was year-round. At any one time, 100 to 120 cattle were in milk, producing a mean of 25 $\mathrm{kg}$ per cow per day. The size of the herd was fixed, and it varied only when barren cattle were removed or heifers were introduced. The area of grazing forage made available varied according to the sward height. For tall swards (approximately $50 \mathrm{~cm}$ high), an area of about $3 \mathrm{~m}^{2}$ per cow per day was available. The area was increased to over $10 \mathrm{~m}^{2}$ per cow per day when pasture swards were approximately $10 \mathrm{~cm}$ high. Cattle were offered concentrate while being milked (4.5\% oil, $18 \%$ protein, 9\% fiber, and $8.6 \%$ ash; green Feed Hi Starch 18, Associated British Nutrition, Cambridgeshire, UK). The amount of concentrate offered varied according to yield, with individuals producing over $30 \mathrm{~kg} / \mathrm{d}$ of milk receiving 8 to $9 \mathrm{~kg} / \mathrm{d}$ of concentrate. This decreased to 3 to $4 \mathrm{~kg} / \mathrm{d}$ at the end of lactation.

The grazing area covered approximately 50 ha of permanent pasture, which consisted of the perennial rye grass (Lolium perenne) reseeded every $4 \mathrm{yr}$. Cattle were rotated around 16 fields, some of which were cut several times for silage before being used for grazing. Field areas varied from 0.4 to 5 ha and took from one to $7 \mathrm{~d}$ to graze. Fields were fertilized with $200 \mathrm{~kg} / \mathrm{ha}$ of $25: 5: 5$ NPK in the spring before any grazing took place and then subsequently with 150 to $200 \mathrm{~kg} / \mathrm{ha}$ 25:5:5 NPK after each grazing rotation. At the beginning of the grazing year, cattle were strip-grazed and provided with approximately $0.4 \mathrm{ha} / \mathrm{d}$ and $0.4 \mathrm{ha} /$ night of fresh pasture, both areas of which were depleted after 12 h. Later in the season (September, October) when the growth rate of the sward declined, they were allowed to graze whole fields. Strip grazing is defined as: the rationing of herbage in a paddock so that sections of the paddock are made available to livestock in a preplanned sequence. A moveable (often electric) fence is the usual method of controlling stock access to the next 
part of the paddock. This system may be varied to include back fencing to stop stock from moving back onto previously grazed parts of the paddock. Rotation grazing is defined as the rotation of livestock around a number of paddocks, such that any one paddock is not continuously stocked but is grazed and rested regularly. During each rotation, the whole area of the paddock is available to livestock for grazing.

\section{Data Collection}

Sources of badger contamination, which included latrines and crossing points, were identified in each of the field systems. Badger latrines were classified on a scale of 0 to 5 , with 5 being the most active. Ranks were determined as: 0 if there was no sign of badger activity but the area had been in use as a latrine in the previous rotation, 1 if there were single old feces, 2 if there were single fresh feces, 3 if there were more than one old feces, 4 if there were more than one fresh feces, and 5 if there were numerous old and fresh feces.

The activity of cattle at areas of badger-contaminated pasture (latrines and crossing points) was directly monitored using an active transponder system (Hutchings and Harris, 1996, 1997). Each cow was tagged with a Cotag 911 transponder (Bewator Cotag Ltd. Surrey, UK), attached to an Allflex superfast large livestock ear tag (Allflex Europe Ltd, Hawick, UK) by a cable tie. Within fields, plots of $1.0 \mathrm{~m}^{2}$ were monitored in areas of badger latrines, crossing points, and control areas, by burying loop aerials around the sites $2 \mathrm{~cm}$ under the ground. Control and contaminated areas were roughly $10 \mathrm{~m}$ apart. Aerials were connected to a controller (Cotag $4010 \mathrm{CDP}$ ) that recorded the identity, time, number, and duration of contacts made by individual cows. The reading field of aerials was adjusted so that cattle standing with their heads raised would not be recorded until their heads were lowered for investigation or grazing. Previous studies in beef cattle, in which grazing behavior was observed over several days, have defined investigative recordings as contacts lasting $<30 \mathrm{~s}$, and grazing recordings as contacts $>30 \mathrm{~s}$ (Hutchings and Harris, 1996; Daniels et al., 2001). Grazing duration is defined as the maximum total duration of all contacts $>30$ s long and contact duration as the maximum duration of all contacts, investigative and grazing. The rates of sward loss at monitored areas were correlated with the time spent grazing as recorded by transponders. In the current study, there was also a positive correlation between the rate of sward loss $(\mathrm{cm} / \mathrm{d})$ and the total length of grazing contact $(\mathrm{min})$ at monitored areas $\left(\mathrm{r}^{2}=\right.$ $0.701, P=0.002$, data pooled for all grazing contacts). Therefore, we use the same contact durations, as they are likely to reflect grazing and investigative behavior.
Use of the 30-s cutoff point also allows a direct comparison with the earlier studies. We deployed 36 aerials in strip-grazed fields and 18 in rotation-grazed fields. Samples of the sward were cut (roughly $100 \mathrm{~cm}^{2}$ to within $2 \mathrm{~cm}$ of the soil surface) to remove the portion of sward ingested by cattle (Phillips, 1993) from each type of site (latrines, crossing points, and their control areas). Samples were analyzed for DM by drying to constant weight $\left(60^{\circ} \mathrm{C}\right), \mathrm{N}$ content using the method of Pella and Colombo (1973) and organic matter digestibility (OMD) using the method of Alexander and McGowan (1966). For every monitored rotation, 10 random sward heights were measured to the nearest $0.5 \mathrm{~cm}$ for each latrine, crossing point, and control area using a sward stick (Barthram, 1985). In addition, 4 random sward heights were measured at each of 10 random locations around areas of fresh cow feces (i.e., deposited during the current rotation) and 4 random sward heights at each of 10 random locations around areas of old cow feces (i.e., deposited during a previous rotation) for every rotation in which cattle were monitored (Phillips, 1993). Thus, depletion of swards (an indication of avoidance behavior) contaminated with cattle as well as badger feces was determined. Because sward height varied between fields and cattle may spend more time grazing in the edge of fields compared with the center (Phillips, 1993), control measurements of sward heights were measured in every monitored rotation. "W" transects were taken of 40 random sward measurements from the center of each field and 40 random measurements were from field edges. For each rotation, an initial set of sward heights were taken the day before cattle were released. When cattle were strip-grazed, sward heights were taken 2 to $4 \mathrm{~h}$ after they had been released and at 24-h intervals until removed. When cows were allowed to graze whole fields, sward heights were only taken at 24 -h intervals.

\section{Statistical Analyses}

Sward characteristics were compared across all treatment types and control regions using analysis of variance. In addition, because latrines and crossing points were always paired with their own individual control, pairwise $t$-tests were performed to compare contaminated regions with their control regions. Residual maximum likelihood was used in GenStat (Lawes Agricultural Trust, 1993) to investigate the effect of the type of contamination (badger latrine, badger crossing point, cow feces contaminated area, or control area) and the management type (strip grazing or rotation grazing), firstly on the proportion of sward depleted and secondly on various transponder variables at monitored sites (number of individuals that grazed, number of individu- 
Table 1. Mean values of initial sward surface height (INIssh, cm), final sward surface height (FINssh, $\mathrm{cm}$ ), sward nitrogen content $(\mathrm{N}, \mathrm{g} / \mathrm{kg} \mathrm{DM})$, and organic matter digestibility (OMD, g/kg DM) for latrines, latrine controls, crossing points, crossing-point controls, areas contaminated with old and fresh cow feces, and control areas in middle and edge of fields, respectively. $P$ and SED denote the probability value and the average standard error of the differences, respectively, for each variate.

\begin{tabular}{lcccc}
\hline Contamination type & INIssh & FINssh & $\mathrm{N}$ & OMD \\
\hline Latrine & 14.94 & 11.41 & 34.8 & 704 \\
Latrine control & 17.41 & 8.26 & 26.8 & 709 \\
Crossing point & 15.96 & 9.72 & 33.7 & 677 \\
Crossing-point control & 22.00 & 8.69 & 24.7 & 697 \\
Old cow feces & 23.13 & 15.20 & $\ldots$ & $\ldots$ \\
Fresh cow feces & 23.13 & 12.73 & $\ldots$ & $\ldots$ \\
Middle field control & 22.86 & 9.09 & $\ldots$ & $\ldots$ \\
Edge Field control & 19.12 & 8.49 & $\ldots$ & 2.3 \\
SED & 3.326 & 1.335 & 2.80 & 0.63 \\
$P$ & 0.009 & $<0.001$ & $<0.001$ & \\
\hline
\end{tabular}

als that investigated, total number of contacts, total number of grazed contacts, and total number of minutes grazed). The proportion of sward depleted was arcsine transformed before analysis to improve its normality (Zar, 1984). Residual maximum likelihood is an iterative method for fitting mixed models to unbalanced datasets, allowing the significance of both factors and covariates to be assessed, and producing estimates of means and standard errors of differences between factor levels (Patterson and Thompson, 1971). For the proportion of sward depleted, the covariates included were: area of field, latrine activity, initial sward surface height, number of days cattle were allowed to graze the latrine or crossing point, and number of days cattle were grazed in a particular strip-grazed field before access to latrine or crossing point (this last covariate is only applicable to strip grazing). For the transponder variables, additional covariates were included: final sward surface height, initial field height minus initial latrine height (a measure of the choice of sward height cattle were presented with) and the $\mathrm{N}$ content of the sward. Note that the level of latrine activity is strictly an ordinal variable (with levels 0 to 5), although in the results quoted we have included it as a continuous variable. Additional analyses treating activity as a factor were carried out to ensure that this approximation was appropriate.

The results presented show both the effects of individual covariates and the main effects of contamination type and management type after allowing for the important covariates. When 2 or more covariates were significant $(P<0.05)$, the correlation between them was inspected. If this correlation was significant $(P<0.05)$, only the more significant of the 2 covariates was retained in the model. Wald tests from the REML analyses were used to quantify the significance of the fixed effects, with the factor in question being fit last in the model and hence its significance adjusted for all other terms in the model. The significance of Wald statistics (W) can be obtained approximately by comparison with a chi-squared distribution, with relevant degrees of freedom (Lawes Agricultural Trust, 1993).

\section{RESULTS}

\section{Sward Characteristics}

There were significant differences in the initial sward surface height across all measured areas (latrines, latrine controls, crossing points, crossing-point controls, old cow feces contaminated areas, fresh cow feces contaminated areas, middle of field control areas, and edge of field control areas; $\mathrm{F}_{7,89}=2.87, P=0.009$; Table 1). Initial sward surface heights of latrines were lower than field-control areas and areas contaminated with cow feces, but there were no significant differences between the different types of control areas. There were no differences in initial sward surface heights between latrines, crossing points, and their associated local controls (paired $t_{31}=1.06, P=0.3$ for latrines and $t_{7}=1.34$, $P=0.22$ for crossing points).

There were significant differences in the final sward surface height across measured areas $\left(\mathrm{F}_{7,89}=8.33, P<\right.$ 0.001; Table 1). Pasture areas contaminated with old cow feces had significantly higher final sward surface heights than all other areas. However, there was no significant difference in final sward surface height between the different control areas. Latrines had significantly higher final sward surface heights than associated control areas but crossing points did not $\left(t_{34}=\right.$ 2.92, $P=0.007$ for latrines and $t_{10}=0.85, P=0.42$ for crossing points).

The $\mathrm{N}$ content of swards differed among the 4 monitored areas (latrines, latrine controls, crossing points, crossing-point controls $)\left(\mathrm{F}_{3,53}=8.93, P<0.001\right.$, Table 1). Swards from latrines and crossing points had higher levels of nitrogen than associated control areas 
Table 2. Significance of effects of the covariates: field area (area, ha), latrine activity (activity), the number of days cattle were grazed in a particular field before access to the latrine or crossing point (dbefore, days), the number of days grazed (dgrazed, days), the initial sward surface height (INIssh, $\mathrm{cm}$ ), and the final sward surface height (FINssh, cm); on the proportion of sward depleted. W, $P$, and $+/-$ denote the Wald statistic, the probability value and the direction of the relationship respectively for each variate. All Wald statistics are quoted for one degree of freedom.

\begin{tabular}{lccc}
\hline Covariate & W & $P$ & + - \\
\hline Area & 0.2 & 0.65 & - \\
Activity & 0.4 & 0.53 & - \\
dbefore & 3.1 & 0.08 & + \\
dgrazed & $<0.01$ & $>0.99$ & - \\
INIssh & 44.5 & $<0.001$ & + \\
FINssh & 11.2 & $<0.001$ & - \\
\hline
\end{tabular}

( $t_{46}=4.14, P=0.001$ for latrines and $t_{10}=2.94, P=$ 0.01 for crossing points). There was no significant difference in OMD between the 4 monitored areas $\left(F_{3,53}=\right.$ $0.59, P=0.63)$.

\section{Sward Depletion Data: Covariates}

Models were fitted by REML to investigate whether there was any evidence of a number of covariates having an effect on the proportion of the sward depleted. Table 2 shows that the only covariates found to have a significant relationship were initial sward surface height and final sward surface height. Initial sward surface height was positively correlated with final sward surface height $(\mathrm{W}=20.4$, df $=1, P<0.001$ ). Therefore, we included initial sward surface height as the only significant covariate in the final analysis.

\section{Sward Depletion Data: Main Effects}

There was a significant difference in the proportion of sward depleted across all measured types of contamination (Table 3). Latrines were grazed less heavily than control regions and the proportion depleted around areas of old cow feces was less than the proportion depleted around areas of fresh cow feces (LSD multiple comparison of means, $P<0.001$ and $P=0.02$ for latrines versus control regions and areas contaminated with old cow feces versus areas contaminated with fresh cow feces, respectively). However, crossing points were grazed to the same proportion as their control areas $(P=0.29)$, and there was no significant difference in the proportion depleted between control areas in the middle or the edge of fields $(P=0.88)$. Within strip-grazed areas, there was a rapid initial rate of sward depletion, with areas around badger latrines avoided and areas around crossing points less so, producing on average approximately 69,40 , and $70 \%$ of control, latrine, and crossing-point areas de-
Table 3. Predicted mean values of the proportion of sward depleted for latrines, latrine controls, crossing points, crossing-point controls, areas contaminated with old and fresh cow feces, and control areas of middle and edge of fields, as estimated by the REML model for the main effects with the inclusion of significant covariates. SED, W, $\mathrm{df}$, and $P$ denote the average standard error of the differences, the overall Wald statistic, the number of degrees of freedom, and the probability value.

\begin{tabular}{lc}
\hline Contamination type & Mean \\
\hline Latrine & 0.425 \\
Latrine control & 0.705 \\
Crossing point & 0.735 \\
Crossing-point control & 0.818 \\
Old cow feces & 0.518 \\
Fresh cow feces & 0.691 \\
Middle field control & 0.786 \\
Edge Field control & 0.774 \\
SED & 0.079 \\
W & 60.2 \\
df & 7 \\
$P$ & $<0.001$ \\
\hline
\end{tabular}

pleted respectively within $24 \mathrm{~h}$ (Figures $1 \mathrm{a}$ and $1 \mathrm{~b}$ ). The proportion depleted at cow feces-contaminated areas was similar to badger feces-contaminated areas, although swards contaminated with cow feces were not grazed to the same depth (Figure 1c). Overall depletion was significantly greater in strip-grazed than rotation-grazed fields $(\mathrm{W}=8.4, \mathrm{df}=1, P=0.004$ ) producing eventual sward depletion levels of 0.75 and 0.35 , respectively. The rate of depletion was also greater when cattle were strip grazed (Figure 2). There was no significant interaction between the type of contamination and the type of rotation in relation to the proportion of sward depleted $(\mathrm{W}=9.5, \mathrm{df}=7$, $P=0.22$ ).

\section{Herd Activity at Transponder Sites: Covariates}

The number of grazing contacts and the time spent grazing at monitored sites (latrines, crossing points, and their controls) increased with the area of the field (Table 4). The number of investigative (but not grazing) contacts increased with latrine activity. The time cattle spent grazing at monitored areas increased with the number of days they were in the field before reaching a monitored area, but the total number of different cattle grazed and the number of grazing contacts did not. This indicates that if a contaminated sward is present in an "early" strip of a field, cattle rapidly deplete the contaminated area with few grazing bouts, and thereafter do not graze there. In contrast, if a contaminated sward is present in a "later" strip of the field, and cattle have the choice to back-graze over the previously grazed area of the field, then grazing at the contaminated sward is less effectual, with slower rates of depletion per grazing bout. 

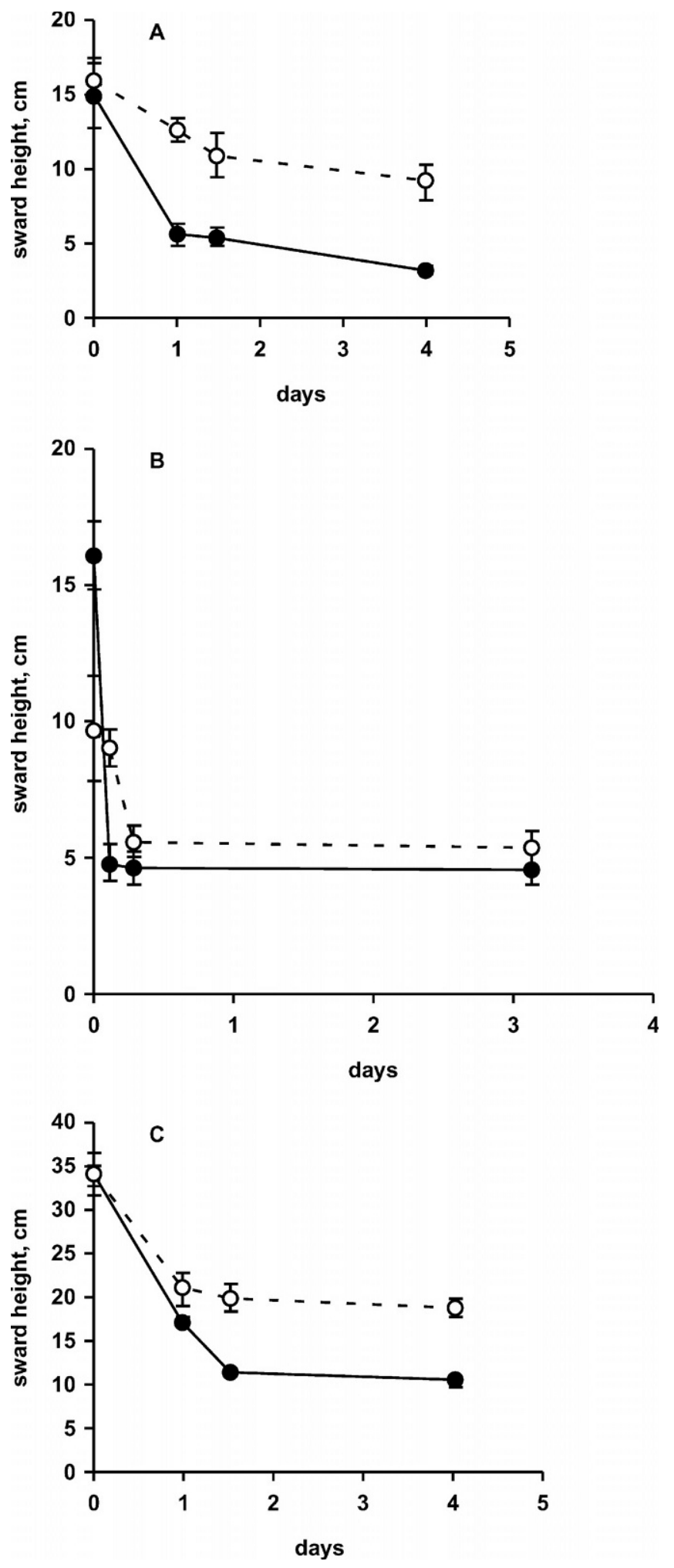

Figure 1. Example of sward depletion (cm) against time (days) in a strip-grazed field for (a): a latrine, (b) a crossing point and (c) areas contaminated with cow feces. Closed and open symbols denote control and contaminated areas, respectively. Error bars denote +/standard errors.

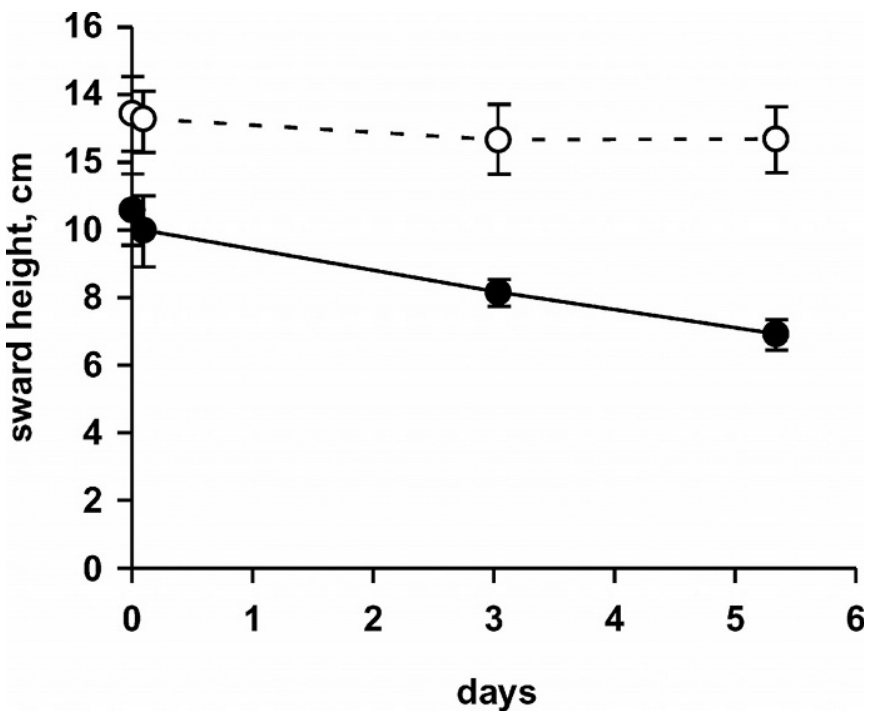

Figure 2. Example of sward depletion ( $\mathrm{cm}$ ) against time (days) in a rotation-grazed field for a latrine. Closed and open symbols denote control and contaminated areas, respectively. Error bars denote +/ - standard errors.

Initial sward surface height of monitored areas was positively correlated with the number of minutes grazed; cattle spent a longer time grazing areas of swards that were taller. The final sward surface height of monitored areas was negatively correlated with the number of grazing contacts; a large number of grazed contacts produced a low final sward surface height. The nitrogen content of the sward was negatively correlated with the number of different cattle grazed, the total number of grazing contacts and the total time spent grazing. Fewer cattle grazed with fewer contacts and for a shorter time when the nitrogen content of the sward was high. The number of days cattle spent in the field before reaching a latrine was not significantly correlated with the number of days that latrine was grazed ( $\mathrm{W}=0.2, \mathrm{df}=1, P=0.66)$. Therefore, we included both covariates in the final analysis. The remaining covariates were nonsignificant (Table 4).

\section{Herd Activity at Transponder Sites: Main Effects}

Throughout the study, 16 badger latrines and 10 crossing points were monitored for a total of $2166 \mathrm{~h}$ during which 621 cattle contacts were recorded. Of these contacts, 238 were grazing contacts and 383 were investigative contacts. Overall 14, 18, 9, and $16 \%$ of the herd contacted latrines, latrine controls, crossing points, and crossing-point controls, respectively, out of approximately 120 animals that were present at any one time in any one rotation. There was a significant difference in the total number of grazing con- 
Table 4. Significance of effects of the covariates: field area (area, Ha), latrine activity (activity), the number of days cattle were grazed in a particular field before access to the latrine or crossing point (dbefore, days), the number of days grazed (dgrazed, days), the initial sward surface height (INIssh, cm), the final sward surface height (FINssh, cm), the initial field height minus the initial latrine sward surface height (sfh-slh), and the sward nitrogen content ( $\mathrm{N}, \mathrm{g} / \mathrm{kg}$ dry matter); on the total number of cattle grazed (No_grazed), the total number of cattle investigated (No_invest), the total number of contacts (Tcontacts), the total number of grazing contacts (Tgcont) and the total number of minutes grazed (Mins). W, $P$, and + --- denote the Wald statistic, the probability value, and the direction of the relationship respectively for each of the covariates. All Wald statistics are quoted for one degree of freedom.

\begin{tabular}{|c|c|c|c|c|}
\hline Variable & Covariate & W & $P$ & $+/-$ \\
\hline \multirow[t]{8}{*}{ Nograzed } & area & 2.0 & 0.16 & + \\
\hline & actvity & 2.9 & 0.09 & + \\
\hline & dbefore & 1.4 & 0.24 & + \\
\hline & dgrazed & 3.2 & 0.07 & - \\
\hline & INIssh & 3.6 & 0.06 & + \\
\hline & FINssh & 0.3 & 0.58 & - \\
\hline & sfh-slh & $<0.0$ & 0.99 & - \\
\hline & $\mathrm{N}$ & 31.2 & $<0.01$ & - \\
\hline \multirow[t]{8}{*}{ No_invest } & area & 0.5 & 0.48 & - \\
\hline & activity & 5.3 & 0.02 & + \\
\hline & dbefore & 0.2 & 0.65 & + \\
\hline & dgrazed & 0.1 & 0.75 & + \\
\hline & INIssh & 0.1 & 0.75 & - \\
\hline & FINssh & 1.0 & 0.32 & - \\
\hline & sfh-slh & 0.5 & 0.48 & - \\
\hline & $\mathrm{N}$ & 1.0 & 0.32 & + \\
\hline \multirow[t]{8}{*}{ Tcontacts } & area & 1.7 & 0.19 & + \\
\hline & activity & 0.1 & 0.75 & + \\
\hline & dbefore & 0.8 & 0.37 & + \\
\hline & dgrazed & 0.9 & 0.34 & - \\
\hline & INIssh & 0.2 & 0.65 & + \\
\hline & FINssh & 2.0 & 0.16 & - \\
\hline & sfh-slh & 0.6 & 0.44 & - \\
\hline & $\mathrm{N}$ & 0.1 & 0.75 & + \\
\hline \multirow[t]{8}{*}{ Tgcont } & area & 6.8 & 0.01 & + \\
\hline & activity & 1.6 & 0.21 & + \\
\hline & dbefore & 2.3 & 0.13 & + \\
\hline & dgrazed & 4.0 & 0.05 & - \\
\hline & INIssh & 2.7 & 0.10 & + \\
\hline & FINssh & 4.2 & 0.04 & - \\
\hline & sfh-slh & 0.6 & 0.44 & - \\
\hline & $\mathrm{N}$ & 12.2 & $<0.01$ & - \\
\hline \multirow{8}{*}{ Mins } & area & 12.5 & 0.00 & + \\
\hline & activity & 0.1 & 0.75 & + \\
\hline & dbefore & 7.6 & 0.01 & + \\
\hline & dgrazed & 28.4 & $<0.01$ & - \\
\hline & INIssh & 5.5 & 0.02 & + \\
\hline & FINssh & 0.9 & 0.34 & - \\
\hline & sfh-slh & 0.2 & 0.65 & + \\
\hline & $\mathrm{N}$ & 8.8 & $<0.01$ & - \\
\hline
\end{tabular}

tacts and in the number of minutes grazed between different contamination types (Table 5). A higher proportion of the herd investigated a contaminated sward than grazed it. On average 7.9 and $5.0 \%$ of the herd investigated a latrine and a crossing point, respectively, compared with 3.3 and $4.5 \%$ of the herd that grazed these areas. Crossing points were grazed less frequently and for a shorter time than their associated controls $(P=0.04$ and $P=0.03$ for the number of grazing contacts and the number of minutes grazed respectively) but latrines were not $(P=0.45$ and $P=$ 0.40 , respectively). Cattle grazed monitored areas for a significantly longer time when they were allowed to graze whole fields, compared with when they were strip-grazed (Table 5). However, there was no significant difference in the number of grazing contacts at monitored areas between rotation- and strip-grazed fields ( $\mathrm{W}=1.0, \mathrm{df}=1, P=0.32$ ).

\section{DISCUSSION}

The overall aim of this study was to further our understanding of disease transmission in intensive agricultural landscapes and assess the possible risks associated with different farming practices. Pathogens and nutrients associated with fecal deposits are heteroge- 
Table 5. Predicted mean values of the total number of grazing contacts (Tgcont) and the total number of minutes grazed (Mins) for the different contamination types: latrines, latrine controls, crossing points and crossing-point controls; and for the different rotation types: strip grazing and rotation grazing, as estimated by the REML model for the main effects with the inclusion of significant covariates. SED, $\mathrm{W}$, df, and $P$ denote the average standard error of the differences, the overall Wald statistic, the number of degrees of freedom and the probability value for each comparison.

\begin{tabular}{lc}
\hline Contamination type & Tgcont \\
\hline Latrine & 4.35 \\
Latrine control & 5.72 \\
Crossing point & 3.65 \\
Crossing-point control & 6.78 \\
SED & 1.53 \\
W & 15.80 \\
df & 3 \\
$P$ & 0.001 \\
& Mins \\
Latrine & 6.24 \\
Latrine control & 6.95 \\
Crossing point & 3.75 \\
Crossing-point control & 5.38 \\
SED & 0.83 \\
W & 10.60 \\
df & 3 \\
$P$ & 0.01 \\
Rotation type & Mins \\
Strip-grazing & 4.46 \\
Rotation-grazing & 7.52 \\
SED & 1.28 \\
W & 5.50 \\
df & 1 \\
$P$ & 0.02 \\
\hline
\end{tabular}

neously distributed in natural and agricultural grazing systems creating trade-offs between the costs associated with disease transmission and the benefits of nutrient intake (Hutchings et al., 1999, 2000, 2001, 2002). The grazing decisions of herbivores in relation to these distributions determine their relative disease risk and nutrient intake and thus fitness and survival (Cooper, 1997; Hutchings et al., 1999, 2001). Bovine tuberculosis acquired, potentially, through contact with swards contaminated by badger excreta is a suitable model to examine disease risk in agricultural systems as there are two possible routes of transmission, aerosolized inhalation of contaminated droplets in a sward (via investigative sniffing) and ingestion of a contaminated sward (via grazing). In order to achieve our overall objective, it was first necessary to determine if a trade-off of nutrition versus TB risk is present in intensive grazing systems.

\section{Sward Characteristics}

Cattle are attracted to taller and darker areas of vegetative swards because they offer increased forage and nutrient intake rates (Black and Kenney, 1984;
Bazely, 1990). These areas may include badger latrines (presence of both feces and urine) and crossing points (presence of urine but no feces). In nutrient-poor systems, such as organically farmed beef cattle, the fertilizing effect of badger excreta on background sward characteristics is likely to be more marked than in intensive farming systems (Haynes and Williams, 1993). In intensive systems, the use of fertilizers may mask the effects of badger excreta on sward characteristics rendering contaminated areas less potentially attractive for grazing compared with the rest of the field. Hence, the sward cues associated with badger excreta might be expected to differ between extensive and intensive agricultural systems, which may have subsequent effects on grazing behavior. Swards around areas of badger excreta in organic beef systems were significantly taller and darker than that of the rest of the field (Hutchings and Harris, 1997). In the current study, latrines and crossing points both had higher levels of nitrogen, but not significantly taller sward surface heights than control areas. This suggests that nutrition versus parasitism trade-offs were present (i.e., excreta and thus potentially TB-contaminated swards were associated with a nutrient advantage) and thus swards associated with badger excreta may have been attractive to grazing cattle while representing a risk of TB.

\section{Effects of Grazing Management}

We compared the grazing behavior of cattle that were strip-grazed with the same individuals that were rotation-grazed. As expected, there was a much more rapid rate of sward depletion in strip-grazed areas compared with rotation-grazed areas. On average, 75\% sward depletion rates were apparent in control areas in 24 $\mathrm{h}$ of strip grazing, whereas only $35 \%$ depletion rates occurred in over $7 \mathrm{~d}$ of rotation grazing. However, it is important to note that strip-grazing and rotationgrazing regimens were not contemporary and some behavioral differences may be associated with changes in sward characteristics across the grazing season. In both regimens, areas around badger latrines were initially avoided, although the period of avoidance was much briefer during strip grazing ( 1 to $2 \mathrm{~h}$ ) than during rotation grazing (several days). This is consistent with cattle grazing behavior in organic beef suckler cattle maintained on a low input rotational grazing system (Hutchings and Harris, 1997). In these studies, cattle initially avoided badger latrines until the noncontaminated sward height was reduced and it was only when competition for uncontaminated sward increased that latrines were eventually grazed. The overall pattern of contact between cattle and badger latrines is therefore consistent across farm management practices and farming 
system (i.e., a period of avoidance followed by grazing). It is only the period of avoidance that is affected. In organic beef systems, approximately $70 \%$ of the herd contact latrines in any one grazing rotation (Hutchings and Harris, 1997). This compares with approximately $14 \%$ of the herd in the present study. Therefore, in extensive systems, badger latrines may be avoided for a longer period of time, resulting in greater levels of investigative contact by a greater proportion of the herd than in intensive systems where latrines are grazed sooner and thus have far less investigative contact by a lower proportion of the herd.

\section{Effects of Different Grazing Regimens on Risks of TB Transmission: Management Recommendations}

In the current study, a higher proportion of the herd investigated badger latrines compared with control areas and the number of investigative contacts at latrines increased with latrine activity. Therefore, the greater the level of rejection of latrines, resulting in relatively tall swards and thus increased attractiveness to herbivores for grazing, the greater the numbers of investigative contacts and thus the possible risk of infection from this route (i.e., investigation but not grazing results in taller swards leading to increased investigation). Although there was no difference in nitrogen content of the sward between badger latrines and crossing points, our results show that there was a difference in the manner that cattle contacted these two areas. Unlike latrines, crossing points were not avoided but grazed more rapidly by fewer individuals than control regions. This suggests that the two-stage contact process by cattle seen at latrines may enhance the risks of TB transmission to cattle herds via investigation through aerosolized inhalation; i.e., cattle are attracted to latrines from a distance but reject them for grazing following olfactory investigation of the badger feces. Following the same arguments, in the case of crossing points (presence of urine but no feces), the high nitrogen content of the sward is likely to have attracted cattle which grazed the sward, depleting it such that it became less attractive to the rest of the herd, resulting in fewer animals grazing the sward and subsequently producing a reduced risk of TB transmission through investigation. Bearing in mind that the chances of contracting TB through aerosolized inhalation are much greater from urine (held in sward in droplets) (Gallagher and Horwill, 1977) than feces (deposited in pits), because both feces and urine are present at latrines, the aversive response of cattle to badger feces may actually put them at a greater risk of transmission from urine at latrines than at crossing points.
Because farm management practices affect the avoidance period of cattle to badger latrines before grazing, they are also likely to affect the risks of TB to cattle posed by the two modes of transmission. If investigative contact is the mode of transmission that represents the greatest risk of TB transmission to cattle, then, all else being equal, low input rotation grazing systems present the greatest risk to cattle from badger latrines. However, if grazing is the main route of TB transmission, then intensive strip grazing systems pose the greatest risk of TB to cattle from badger latrines, as this provides the minimum investigative contact and maximum grazing contact with fresh urine, because TB numbers decline after deposition in the environment (Lepper and Pearson, 1973) and urinations will almost certainly be contacted and grazed in a single day (i.e., urine $<24 \mathrm{~h}$ old) from urine passed the previous night (Brown, 1993).

\section{CONCLUSIONS}

In general, the risks of disease transmission through investigative contacts increase with decreasing stocking density, whereas the risks of disease transmission through grazing contacts increase with increasing stocking density. Manipulation of grazing pressure and sward characteristics may then represent methods of reducing the risks of TB posed to cattle from badger excreta. If the medium in which TB is deposited (i.e., feces and urine) has a large impact on sward characteristics (i.e., nutrient content and height), manipulation of background sward characteristics may be used to reduce the risks of TB transmission. For example, in nutrient-poor systems, fertilization of sward may potentially reduce the attractiveness of badger latrines to cattle and thus decrease the levels of investigative contact. Similarly, given that cattle always show a period of avoidance of contaminated swards, theoretically there is an optimum time to remove cattle from a field before a significant amount of grazing of contaminated swards has taken place. Clearly, farming systems and especially agricultural intensification may have a significant impact on the levels of contact between herbivores and disease in grazing environments. Specifically, in relation to the risks of TB posed to cattle by badgers, the rates of investigative and grazing contact with badger excreta are affected by the type of agricultural system. For these risks to be quantified and specific management recommendations to be made, the probability of TB infection to cattle from grazing and investigative contact with badger excreta must be determined.

\section{ACKNOWLEDGMENTS}

We would like to thank the landowner and farm staff, especially M. and L. Dewar for their help and coopera- 
tion during this study. We would also like to thank the Macaulay Land Use Research Institute for carrying out the organic matter digestibility and the nitrogen analyses on sward samples. This project was funded by the Department of Environment, Food \& Rural Affairs. The Scottish Agricultural College and Biomathematics and Statistics Scotland receive support from the Scottish Executive, Environment and Rural Affairs Department.

\section{REFERENCES}

Alexander, R. N., and M. McGowan. 1966. The routine determination of in vitro digestibility of organic matter in forages - an investigation of the problems associated with continuous large-scale operations. J. Br. Grassl. Soc. 21:140-147.

Arnold, G. E. 1981. Grazing behavior. Pages 79-104 in Grazing animals. F. H. W. Morely, ed. Elsevier, Amsterdam, The Netherlands.

Arnold, G. E. 1987. Influence of the biomass, botanical composition and sward height of annual pastures on foraging behavior of sheep. J. Appl. Ecol. 24:759-772.

Barthram, G. T. 1985. Experimental techniques: The HFRO sward stick. Pages 29-30 in Hill Farming Research Organisation, Biennial Report 1984-85. Penicuik, Scotland.

Bazely, D. R. 1990. Rules and cues used by sheep foraging in monocultures. Pages 343-367 in Behavioral mechanisms of food selection. R. N. Hughes, ed. Springer, Berlin.

Bazely, D. R., and C. V. Ensor. 1989. Discrimination learning in sheep with cues varying in brightness and hue. Appl. Anim. Behav. Sci. 23:293-299.

Benham, P. F. J., and D. M. Broom. 1989. Interactions between cattle and badgers at pasture with reference to bovine tuberculosis transmission. Br. Vet. J. 145:226-241.

Benham, P. F. J., and D. M. Broom. 1991. Responses of dairy cows to badger urine and feces on pasture with reference to bovine tuberculosis transmission. Br. Vet. J. 147:517-532.

Black, J. L., and P. A. Kenney. 1984. Factors affecting diet selection by sheep. II. Height and density of pasture. Aust. J. Agric. Res. 35:565-578.

Brown, J. A. 1993. The transmission of bovine tuberculosis (Mycobacterium bovis) from badgers (Meles meles) to cattle. Ph.D. Diss., Univ. Bristol, UK.

Brown, J. A., S. Harris, and P. C. L. White. 1994. Persistence of Mycobacterium bovis in cattle. Trends Microbiol. 2:43-46.

Cooper, J. 1997. The behavioral control of helminth infection by sheep. Ph.D. Diss., Univ. Aberdeen, UK.

Daniels, M. J., N. Ball, M. R. Hutchings, and A. Grieg. 2001. The grazing response of cattle to pasture contaminated with rabbit faeces and the implications for the transmission of paratuberculosis. Br. Vet. J. 161:306-313.

Edwards, P. J., and S. Hollis. 1982. The distribution of excreta on New Forest grassland used by cattle, ponies and deer. J. Appl. Ecol. 19:953-964.

Gallagher, J., and D. M. Horwill. 1977. A selective oleic acid albumin agar medium for the cultivation of Mycobacterium bovis. J. Hygiene 79:155-160.

Haynes, R. J., and P. H. Williams. 1993. Nutrient cycling and soil fertility in the grazed pasture ecosystem. Adv. Agron. 49:119-199.
Hutchings, M. R., and S. Harris. 1996. An active transponder system for remotely monitoring animal activity at specific sites. J. Zool. (Lond.) 240:798-804.

Hutchings, M. R., and S. Harris. 1997. Effects of farm management practices on cattle grazing behavior and the potential for transmission of bovine tuberculosis from badgers to cattle. Vet. J. 153:149-162.

Hutchings, M. R., and S. Harris. 1999. Quantifying the risks of TB infection to cattle posed by badger excreta. Epidemiol. Infect. 122:167-173.

Hutchings, M. R., I. Kyriazakis, I. J. Gordon, and F. Jackson. 1999. Trade-offs between nutrient intake and fecal avoidance in herbivore foraging decisions: the effect of animal parasitic status, level of feeding motivation and sward nitrogen content. J. Anim. Ecol. 68:310-323.

Hutchings, M. R., I. Kyriazakis, T. G. Papachristou, I. J. Gordon, and F. Jackson. 2000. The herbivores' dilemma: trade-offs between nutrition and parasitism in foraging decisions. Oecologia 124:242-251.

Hutchings, M. R., I. Kyriazakis, and I. J. Gordon. 2001. Herbivore physiological state affects foraging trade-off decisions between nutrient intake and parasite avoidance. Ecology 82:1138-1150.

Hutchings, M. R., J. M. Milner, I. J. Gordon, I. Kyriazakis, and F. Jackson. 2002. Grazing decisions of Soay sheep (Ovis aries) on St Kilda: a consequence of parasite distribution? Oikos 96:235-244.

Krebs, J. R . 1997. Bovine tuberculosis in cattle and badgers. MAFF publications, London, UK.

Lawes Agricultural Trust. 1993. GenStat 5 Reference Manual. Clarendon Press, Oxford, UK.

Lepper, A. W. D., and C. W. Pearson. 1973. The route of infection in tuberculosis of beef cattle. Aust. Vet. J. 49:266-267.

Little, T. W. A., P. F. Naylor, and J. W. Wilesmith. 1982a. Laboratory study of Mycobacterim bovis infection in badgers and calves. Vet. Rec. 111:550-557.

Little, T. W. A., C. Swan, H. V. Thompson, and J. W. Wilesmith. 1982b. Mycobacterium bovis infection in cattle, badgers and other mammals in an area of Dorset. Vet. Rec. 110:318-320.

Ministry of Agriculture, Fisheries and Food. Agricultural and horticultural returns-England and Wales. 1993. HMSO, Guildford, UK.

Morris, R. S., D. U. Pfeiffer, and R. Jackson. 1994. The epidemiology of Mycobacterium bovis infections. Vet. Microbiol. 40:153-177.

Muirhead, R. H., J. Gallagher, and K. J. Burn. 1974. Tuberculosis in wild badgers in Gloucestershire: epidemiology. Vet. Rec. 95:552-555.

Parsons, A. J., J. A. Newman, P. D. Penning, A. Harcey, and R. J. Orr. 1994. Diet preference of sheep: effects of recent diet, physiological state and species abundance. J. Anim. Ecol. 63:465-478.

Patterson, H. D., and R. Thompson. 1971. Recovery of inter-block information when block sizes are unequal. Biometrika 58:545554.

Pella, E., and B. Colombo. 1973. Study of carbon, hydrogen and nitrogen determination by combustion-gas chromatography. Mikrochim. Acta 1973:679-719.

Phillips, C. J. C. 1993. Cattle behavior. Farming press, Ipswich, UK.

Stuart, F. A., and J. W. Wilesmith. 1988. Tuberculosis in badgers: a review. Rev. Sci. Tech. Off. Int. Epiz. 7:929-935.

Sykes, A. R. 1987. Endoparasites and herbivore nutrition. Pages 211232 in Nutrition of Herbivores. J. B. Hacker, and J. H. Ternouth, eds. Academic Press, Harickvale, Australia.

Wilesmith, J. W., T. W. A. Little, H. V. Thompson, and C. Swan. 1982. Bovine tuberculosis in domestic and wild mammals in an area of Dorset. 1. Tuberculosis in cattle. J. Hygiene 89:195-210.

Zar, J. H. 1984. Biostatistical Analysis. Prentice-Hall, Englewood Cliffs, NJ. 